\title{
MODELING SECTORAL ECONOMIC ACTIVITY AT THE SMSA LEVEL: FINANCE, INSURANCE, AND REAL ESTATE\#
}

\author{
J. Kimball Dietrich*
}

Interest in regional economic activity is increasingly focused on the SMSA as the important unit of concern. Glickman (1971) presented an econometric model of Philadelphia, while Hall and Licari (1974) extended Glickman's approach to Los Angeles. These models deal with highly aggregated economic activity in that the local economy is divided into only three sectors: manufacturing, wholesale and retail trade and selected services, and all other (Glickman, p. 17). Furthermore, these models are annual models. For local decision-making purposes, quarterly projections over shorter time horizons would be useful for a variety of economic variables. Some variables, such as deposits, are of immediate interest to private or public planners concerned with local financial markets, while sectoral employment forecasts can be used to build income and revenue projections for planning purposes.

This paper presents an econometric model of finance, insurance, and real estate (FIRE) sectoral economic activity and proves the feasibility and desirability of increased disaggregation and detail in modeling regional economic activity. Regional econometric forecasting models in the future will require substantial regional variation. The approach taken in this paper is to assume that the local industrial complexion, regional regulatory framework, and geographical endowments require special attention.

A quarterly econometric model of employment and its determinants in the FIRE sector for Pima County, Arizona, is presented in this study. This sectoral model is, of course, only part of a complete regional model. ${ }^{1}$ This means that the equations presented here ignore the obvious problems of the simultaneous determination of sectoral employment and aggregate regional economic activity. We may note by way of justification that the total FIRE sector is small relative to total employment in the region, and that simultaneity problems can be resolved upon completion of a total model with known econometric techniques. ${ }^{2}$ The results presented here

\footnotetext{
*Assistant Professor of Finance, University of Arizona, Tucson, Arizona.

\#This paper summarizes an analysis of financial employment conducted as part of a project conducted by the Division of Economic and Business Research of the University of Arizona for the Planning Department of the City of Tucson under the 701 Comprehensive Planning Program of the U.S. Department of Housing and Urban Development.
} 
clearly indicate the benefits of more detailed sectoral modeling at the regional level.

Employment in finance, insurance, and real estate is analyzed in terms of four primary sectors: banking (SIC code 60), nonbank savings institutions, primarily credit unions and savings and loans (SIC code 61), real estate (SIC code 65) and insurance (SIC code 63). All employment data in these categories were gathered monthly from 1964 to 1974 from detailed Arizona Department of Economic Security (DES) sources. The quarterly employment model uses average employment figures derived from these employment data.

\section{The Employment Functions}

The employment functions estimated here are dependent on the level of output of financial sector services provided by each class of employers. Longbrake and Merrill (1976) provide an extensive theoretical discussion of the problems of measuring output in the demands for two classes of financial sector workers, namely commercial bank production and administrative workers. I follow the approach used by Longbrake and Merrill to the extent possible in each of the four classes of employees analyzed here. However, their study was based on extensive data from the Federal Reserve System's functional cost analysis, whereas the output measures available for use here are necessarily more highly aggregated. Since no relative factor cost or other supply variables are available for the FIRE sector, the equations estimated are interpreted as reduced form market equilibrium employment equations.

For banks, savings and loans, and credit unions, outputs consist of loan and deposit processing. Bank demand deposit processing is very labor intensive, despite the advent of computer, and is more sensitive to the number of items than dollar amounts. However, real dollar balances available to banks and savings institutions determine the scale of both deposit and loan operations, in turn determining the number of lending officers, credit personnel, and clerks needed to process loans. For both banks and non-banks, real deposits measured as a three-quarter moving average of demand deposits or savings shares (MADDTC67 and MASLTC67), were the primary determinant of employment levels. ${ }^{3}$ In addition, account activity in the case of banks must be considered, thus a "velocity of money" variable (VELTC), defined as income divided by demand deposits, was included in the model. ${ }^{4}$ These results are shown in lines (1) and (2) of Table 1 .

To forecast the explanatory variables in the employment demand functions for bank and nonbank savings institutions, demand functions for both demand deposits and savings and loan shares were estimated. To reflect the primarily retail nature of these deposits in Arizona due to state-wide branching and the lack of a large financial center, individual saver behavior was hypothesized. Real demand deposits and savings shares are assumed to follow a partial adjustment scheme necessitating lagged values of dependent variables in the regressions. Desired levels of deposits 
TABLE 1

FIRE Sector Regressions-Quarterly Model*

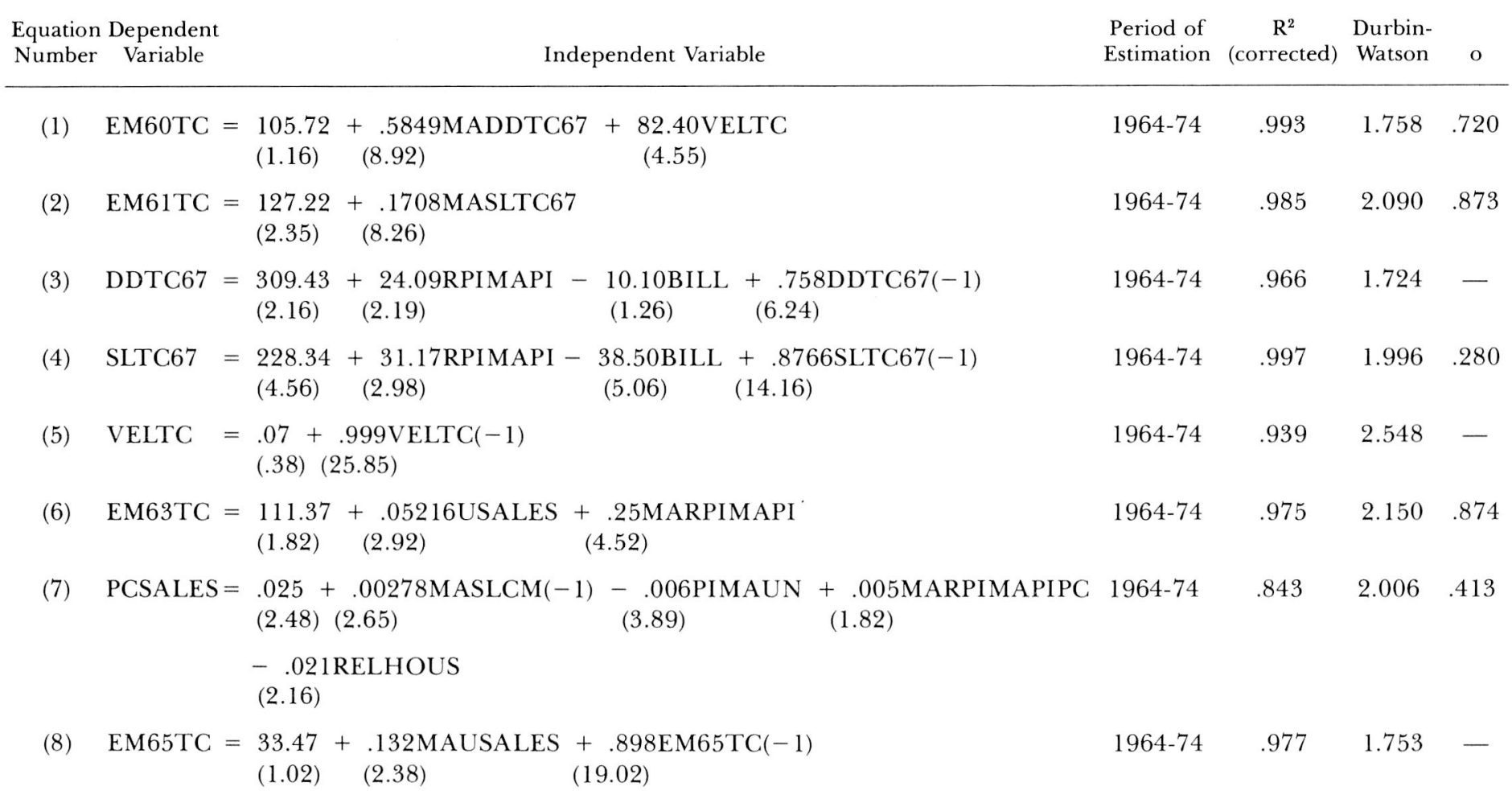


TABLE 1 (continued)

\section{DEFINITION OF VARIABLES}

BILL = 3-month treasury bill rate from Federal Reserve Bulletin.

CPI $=$ consumer price index $(1967=100)$ from Survey of Current Business (SCB.)

DDTC67 = average monthly demand deposits (thousands of dollars) in Tucson from Federal Reserve Bank of Dallas Statistical Supplement, divided by the CPI $(1967=100)$.

EM60TC $=$ employment in SIC 60 (banking institutions) in Pima County from Arizona Department of Economic Security (DES).

EM61TC = employment in SIC 61 (non-banking institutions) in Pima County from DES.

EM63TC = employment in SIC 63 (insurance) in Pima County from DES.

EM65TC = employment in SIC 65 (real estate) in Pima County from DES.

IPDC72 = GNP implicit price deflator for all personal consumption expenditures $(1972=100)$ from SCB.

IPDH72 = GNP implicit price deflator for housing $(1972=100)$ from SCB.

MADDTC67 = three-quarter moving average of DDTC67.

MARPIMAPIPC $=$ three-quarter moving average of RPIMAPI divided by PIMAPOP.

MASLCM = three-quarter moving average of ratio of the change in savings and loan deposits in Tucson headquartered savings and loans to the absolute value of the sum of changes in demand deposits and savings and loan deposits.

MASLTC67 = three-quarter moving average of SLTC67.

MAUSALES = three-quarter moving average of USALES.

PIMAPI $=$ total wage payments in Pima County from DES.

PIMAPOP $\quad=$ Pima County population (1000s) from DES and Division of Economic and Business Research, University of Arizona.

PIMAUN = unemployment rate in Pima County (percent) from DES.

PCSALES = USALES/PIMAPOP.

RELHOUS $=$ IPDH72/IPDC72.

RPIMAPI $=$ PIMAPI/CIP.

SLTC67 = average quarterly savings and loan shares on deposit at Tucson headquartered associations (thousands of dollars) from Arizona Superintendent of Banks, divided by CPI.

USALES $\quad=$ sales of residential housing reported by the Tucson Multiple Listing (number of houses sold).

VELTC = velocity of demand deposits $=($ RPIMAPI/DDTC67) $\times 1000$. 
were assumed to be a function of real personal income (RPIMAPI) and the rate of return on alternative investments for individuals, represented by the 3-month Treasury bill rate (BILL). The resulting equations are shown as lines (3) and (4) on Table 1. As expected, the adjustment speed (seen in the coefficient of the lagged dependent variable) is faster for demand deposits than for savings shares.

Velocity proved a difficult variable to forecast. It was determined that VELTC is related significantly to the bill rate as one would expect, since the higher the opportunity cost of holding money, the less one would want to keep idle. However, the explanatory power of the relation is not high. In view of a secular long-run rise in velocity a good predictor of velocity was derived from a function of lagged VELTC (equation (5) in Table 1).

Insurance employment (EM63TC) consists of employment in the life insurance, casualty insurance, and other insurance, classifications. With no large regional administrative offices for insurance firms in Pima County, the number of new policy sales was assumed to be the important output determining employment in this sector. The two largest classes of insurance sold are life insurance and casualty insurance. Two major determinants of these policy sales are real personal income (RPIMAPI), affecting life insurance and credit life insurance, and newly sold residential real estate, represented by USALES, presumably a major determinant of new casualty policies. A moving average of income was used. Insurance price variables were not included, since insurance premiums are established by actuarial experience and financial earnings and do not change much. These results are shown in lines (6) on Table 1.

The USALES variables was estimated best using a residential housing demand model. ${ }^{5}$ Per capita sales were specified as a function of real per capita income, a measure of mortgage availability (SLCM), the cost of housing relative to other goods (RELHOUS), and the unemployment rate in Pima County (PIMAUN). The latter was included to reflect the fact that pessimism (optimism) about job security, future wages, and general economic outlook tends to discourage (encourage) major consumer investments. These variables were included in lagged and moving average versions in the quarterly model to smooth out temporary fluctuations. The cost of housing relative to other goods is measured by the GNP implicit price deflator for housing relative to the GNP implicit price deflator for personal consumption expenditures. All the variables are significant and have the appropriate signs. The results are given in line (7) of Table 1.

Real estate employment (EM65TC) is concentrated in brokerage of real estate. Property transactions are the primary output of the industry. Therefore, employment is primarily determined by residential housing sales. Since there are training and licensing requirements for salesmen and brokers, immediate adjustment of employment to sales activity is not expected; an appropriate specification is a partial adjustment model requiring inclusion of the lagged dependent variable. The desired level of employment is related to a moving average of sales. The estimated equations are shown on line (8) of Table 1. 


\section{Evaluation of the Estimates}

The estimated equations have high corrected $\mathrm{R}^{2} \mathrm{~s}$ (only one is under .9) and high t-values for most independent variables. In several equations, ordinary least squares estimation produced unacceptable Durbin-Watson statistics, and these equations were reestimated with first-order autocorrelation corrections. The autocorrelation coefficients, when estimated, are shown in the last column of the table. The model must be judged of high explanatory power within the sample period, which ended in 1974.

Further analysis of the model's intrasample performance is based on dynamic simulations of all endogenous variables. For the simulations, only exogenous variable actual values were used, while all endogenous variables were forecasted, including lagged values of endogenous variables. Table 2 presents the root-mean-square-error (RMSQE) for the sample period, as well as the RMSQE as a percent of actual average values. The banking equations work very well while the other sectors have somewhat larger RMSQEs. However, these RMSQEs are not completely representative, as the errors for these equations are much larger in the first half of the sample. The equations work better in the latter period, as can be seen for the employment equation RMSQEs for the period 1970 to 1974 , also given in Table 2.

The sample period predictions of endogenous variables in general have RMSQE of five to fifteen percent of actual average values. The exceptions are SLCM, USALES, and EM61TC. For the case of EM61TC, performance of the model is substantially better in the later period. The SLCM average error is greatly exaggerated by two quarters of exceptionally large errors (196501 and 197402). In general SLCM is much closer to actuals than is reflected by its sample period RMSQE. While there is no absolute standard to judge these results, the generally low RMSQE justifies substantial confidence in the overall approach to modeling employment within the sample, given the large structural shifts and growth experienced in Pima County over the period.

In order to test the predictive power of the model outside the sample period, quarterly forecasts for 1975 levels of employment were generated and compared to actual 1975 values. Actual 1975 values for exogenous variables not determined within the model, namely income, the Treasury bill rate, population, and relative price deflators, were used in making the forecasts, whereas all endogenous variables values were calculated. The forecasted values for all variables determined within the model are shown in Table 3, together with the actual values.

For insurance and real estate employment, the model predictions are extremely close to actual values. All of the forecast errors for these two classifications of employment are within one standard error (of the appropriate estimated regression) from the actual values. This evidence suggests that the model can be considered as very reliable for forecasting real estate and insurance employment, given good forecasts of the exogenous variables.

The forecasts for deposit-taking institutions are not quite as good. 
TABLE 2

Sample Period Predictive Power of FIRE Sector Model

\begin{tabular}{|c|c|c|c|c|}
\hline $\begin{array}{c}\text { Endogenous } \\
\text { Variable }\end{array}$ & RMSQE & $\overline{\mathrm{A}}$ & RMSQE/ $/ \bar{A}$ & Period \\
\hline DDTC67* & 10883.1 & 203147 & .0536 & $194602-197404$ \\
\hline SLTC67* & 10873.1 & 249330. & .0436 & 196402-197404 \\
\hline SLCM* & .7414 & .611724 & 1.212 & $196501-197404$ \\
\hline USALES* & 243.064 & 1035.63 & .2347 & $196501-197404$ \\
\hline VELTC & .0432 & 4.8947 & .0884 & 196403-197404 \\
\hline EM60TC & 56.07 & 1484.48 & .0378 & 196403-196404 \\
\hline$"$ & 40.109 & 1739.4 & .0231 & $197001-197404$ \\
\hline EM61TC & 109.33 & 529.571 & .2064 & 196403-197407 \\
\hline$"$ & 36.239 & 617.050 & .0587 & $197001-197404$ \\
\hline EM63TC & 51.433 & 447.75 & .1149 & $196501-197404$ \\
\hline$"$ & 63.689 & 560.60 & .1136 & $197001-197404$ \\
\hline EM65TC & 186.24 & 1311.12 & .142 & $196403-197404$ \\
\hline$"$ & 232.887 & 1878.85 & .1240 & $197001-197404$ \\
\hline
\end{tabular}

*Moving average errors were uniformly smaller.

$F_{i}=$ Forecast in period $i$

RMSQE $=\sqrt{\frac{\sum_{i=1}^{n}\left(F_{i}-A_{i}\right)^{2}}{N}}$

$\mathrm{A}_{\mathrm{i}}=$ Actual in period $\mathrm{i}$

$\overline{\mathrm{A}}=$ Average actual value.

Employment in banking is forecast very close to actuals (within one or two standard errors) for the first two quarters of 1975 . However, the errors tend to grow larger over time. A large initial underestimation of the model gradually turns into a large overestimate over the four quarters for nonbank credit institutions.

The reasons for these errors are seen in the weakness of the deposit forecasting equations around business cycle turning points. While the demand deposit equation catches the general pattern of change over the first three quarters, all the demand deposit forecasts are too high, and the model missed a downturn in the fourth quarter. For savings and loan deposits, the forecasts start out too low and end up too high. If the deposit 
TABLE 3

Forecast and Actual 1975 Value for Variables Determined by FIRE Sector Model

\begin{tabular}{|c|c|c|c|c|c|c|c|c|}
\hline \multicolumn{9}{|c|}{ Endogenous Variables Determing Employment } \\
\hline & \multicolumn{2}{|c|}{ DDTC67 } & \multicolumn{2}{|c|}{ SLTC67 } & \multicolumn{2}{|c|}{ PCSALES } & \multicolumn{2}{|c|}{ VELTC } \\
\hline Period & Forecast & Actual & Forecast & Actual & Forecast & Actual & Forecast & Actual \\
\hline 197501 & 251614 & 233340 & 352270 & 362700 & .00342 & .00370 & .6823 & .7115 \\
\hline 197502 & 256374 & 242500 & 371184 & 380000 & .00310 & .00401 & .6904 & .6857 \\
\hline 197503 & 258636 & 244108 & 382683 & 391070 & .00279 & .00392 & .6985 & .6743 \\
\hline \multirow[t]{3}{*}{197504} & 262567 & 231329 & 397174 & 384370 & .00291 & .00316 & .7067 & .7387 \\
\hline & \multicolumn{8}{|c|}{ Levels of Employment in FIRE Sector } \\
\hline & EM60 & $0 \mathrm{TC}$ & EM6 & $1 \mathrm{TC}$ & EM63 & $3 \mathrm{TC}$ & EM6 & $5 \mathrm{TC}$ \\
\hline Period & Forecast & Actual & Forecast & Actual & Forecast & Actual & Forecast & Actual \\
\hline 197501 & 1892 & 1847 & 756 & 817 & 577 & 545 & 2049 & 2007 \\
\hline 197502 & 1922 & 1856 & 762 & 805 & 577 & 570 & 2055 & 2084 \\
\hline 197503 & 1956 & 1847 & 780 & 805 & 573 & 594 & 2065 & 1944 \\
\hline 197504 & 1987 & 1716 & 803 & 751 & 583 & 615 & 2065 & 2028 \\
\hline
\end{tabular}

Exogenous Variables: BILL, RPIMAPI, RELHOUS, PIMAUN, PIMAPOP. Derived Values for MADDTC67, MASLTC67, MASLCM and MAUSALES are not shown.

forecasts had been closer to actual figures, the employment figures would have been closer than actuals. This analysis points up a possible weakness in the model, since it is notoriously difficult to pick up turning points in financial market variables.

\section{Summary}

The quarterly model of financial employment and its determinants discussed above provides a great deal of encouragement to detailed regional modeling of economic activity. The statistical precision of the model within the sample period is high, and as the dynamic simulations indicate, better in the later time span. The logic of the relationships hypothesized here are gratifyingly reflected in the coefficients of the regressions. The postsample analysis of the quarterly model indicated that the model func- 
tions well, but one must be wary of problems associated with forecasting turning points in the business cycle. There is no doubt, however, that the approach is warranted by improved analytical detail in the interaction of localized economic variables and in heightened awareness of the determinants of local employment.

\section{FOOTNOTES}

1. An annual model for Pima County has been developed by the Division of Economic and Business Research of the University of Arizona, under contract with the Planning Department of the City of Tucson. Annual equations similar to those reported here are a part of the complete Pima County model.

2. In the complete annual model, the entire model, including 36 categories of employment, four components of personal income, retail and restaurant sales and population, is solved using the University of Michigan Economic Forecasting Package. The annual equations corresponding to the quarterly model for the FIRE sector include as endogenous variables certain variables considered exogenous here, but the specification of those equations did not differ mar- kedly from the least squares estimates, such as are presented here for the quarterly model.

3. Longbrake and Merrill (1976) used number of accounts and average account balance in their individual bank demand functions. Comparable detailed data were not available for this study.

4. Longbrake and Merrill (1976) used a number of activity measures, such as number of deposits per account, etc., in their estimated demand functions, which are similar in spirit to the velocity variable used here.

5. I am grateful to Carol Taylor for assistance in specification in this relationship, based upon her work in the residential construction sector.

\section{REFERENCES}

1. Glickman, N.J. 1971. "An Econometric Forecasting Model for the Philadelphia Region," Journal of Regional Science (April), pp. 15-32.

2. Hall, P.P. and Licari, J.A. 1974. "Building Small Region Econometric Models: Extension of Glickman's Structure to Los Angeles," Journal of Regional Science, 14, pp. 337-353.

3. Longbrake, W.A. and Merrill, H.D. 1976. "De- mand for Commercial Bank Production Workers and Administrators," Journal of Money, Credit, and Banking, August, pp. 275-295.

4. Mattila, J.M. 1973. “A Metropolitan Income Determination Model and the Estimation of Metropolitan Income Multipliers," Journal of Regional Science (April), pp. 1-16. 